\title{
CHINA E BRASIL NA ÁFRICA SUBSAARIANA E A RETOMADA DA QUESTÃO NACIONAL
}

Diego Pautasso

Resumo: O objetivo O presente trabalho é analisar as relações de China e Brasil com a África Subsaariana. Não se trata, entretanto, de focar na evolução do relacionamento em si, mas de como este novo eixo de interação tem retomado a questão nacional. O argumento central é que os países emergentes, ao promover a soberania e o desenvolvimento no continente africano, têm tido uma atuação que não se adequa ao conceito de (sub)imperialismo. Em outras palavras, o relacionamento Sul-Sul e a retomada da questão nacional têm sido justamente a alternativa aos países periféricos diante do quadro de forças surgido no Pós-Guerra Fria.

Palavras-chaves: China, Brasil e África Subsaariana; Questão Nacional; (Sub)imperialismo

\section{CHINA AND BRAZIL IN SUB- SAHARAN AFRICA, AND THE REBIRTH OF THE NATIONAL QUESTION}

\section{Diego Pautasso}

Doutor em Ciência Política pela Universidade Federal do Rio Grande do Sul (UFRGS) e professor de Relações Internacionais e pesquisador do NEPRI na Escola Superior de Propaganda e Marketing (ESPM) Sul.

\begin{abstract}
The aim of this paper is to analyze the relations of China and Brazil, with subSaharan Africa. It is not, however, focus on the evolution of the relationship itself, but how this new axis of interaction has taken over the national question. The central argument is that emerging countries, to promote the sovereignty and development on the African continent, have had a performance that does not fit the concept of (sub)imperialism. In other words, the South-South relations and the resumption of the national question have been precisely the alternative to peripheral countries before the picture of forces emerged in the Post-Cold War.
\end{abstract}

Keywords: China, Brazil and sub-Saharan Africa; National Question; (Sub)imperialism 


\section{INTRODUÇÃO}

Ao invés de um cenário momentâneo e artificial de unipolaridade, o sistema internacional tem sido marcado por um complexo reordenamento do poder mundial. Uma das novas faces da nova ordem é a projeção dos países emergentes e o fortalecimento das relações Sul-Sul. Nesse sentido, o objetivo do presente trabalho é analisar as relações de China e Brasil com a África Subsaariana. Não se trata, entretanto, de focar na evolução do relacionamento em si, mas de como este novo eixo de interação tem retomado a questão nacional. Apesar da polissemia ${ }^{1}$ do termo, a questão nacional é aqui entendida como reforço da soberania e da agenda do desenvolvimento. O argumento central é que o relacionamento desses países emergentes com o continente africano, apesar de possuírem padrões diferenciados, não só não reproduzem práticas (sub)imperialistas, como apresentam, em muitos aspectos, uma atuação anti-imperialista. Em outras palavras, diante do quadro de forças surgido no Pós-Guerra Fria, o relacionamento Sul-Sul e a retomada da questão nacional têm sido justamente a alternativa aos países periféricos e o contraponto à política unilateral dos EUA de expansão do seu poder baseado no recurso à força.

Para dar conta dessa discussão, organizamos o trabalho em três seções. A primeira seção discute a reestruturação do capitalismo pós-1970 e o reordenamento do poder mundial que o acompanhou, traçando os fatores que levaram à crise da questão nacional nos anos 1990 e a posterior retomada no século XXI. A segunda, aborda como se deu a inserção da África Subsaariana nessa nova correlação de forças. Por fim, a reflexão se fecha ao relacionar o papel dos países emergentes no continente africano como parte dessa retomada da questão nacional e os consequentes impactos para a ordem mundial.

1 Para uma discussão acerca da questão nacional, sugere-se ver Um mapa da questão nacional, organizado por Gopal Balakrishnan (2000). 


\section{DA CRISE À RETOMADA DA QUESTÃO NACIONAL}

A década de 1970 representou um movimento de inflexão na economia e nas relações internacionais. De um lado, a crise do petróleo e a perda de dinamismo do centro do sistema forçaram a reestruturação da economia mundial, incluindo o desencadeamento de uma nova divisão internacional da produção, a revolução científico-tecnológica e a adoção de políticas liberalizantes. Como destacou Chesnais (2000), tratou-se de promover um novo regime de acumulação saído de um contexto de reação neoconservador sob os auspícios de Thatcher e Reagan, isto é, voltados a retomar a rentabilidade por meio de políticas de regressão social e da ampliação dos ganhos financeiros em escala global. De outro, o fim da Guerra Fria gerou um cenário momentâneo e artificial de unipolaridade no sistema internacional, na medida em que os EUA viram a superpotência rival, a URSS, se desintegrar junto com sua esfera de influência.

O discurso da globalização se fortaleceu justamente nesse quadro de supremacia dos EUA, de fortalecimento de alguns organismos internacionais e de imposição da agenda liberalizante. Como destaca Fernandes (1998a, p. 19), nesse contexto tornou-se recorrente confundir globalização, enquanto processo objetivo de integração global, com agenda (neo)liberal, enquanto políticas orientadas à desestatização de empresas públicas, desregulamentação da economia e desuniversalização de direitos. Na verdade, como sublinha o mesmo autor, tal confusão conceitual buscou dar à globalização (neoliberal) um caráter irreversível. É nesse bojo que se difundiram concepções voltadas a fragilizar o conceito de Estado e, com efeito, desarticular a ideia de soberania, projeto nacional e desenvolvimento. É ilustrativa a produção intelectual da época, com obras como O fim da História (1992), de Fukuyama; O fim dos territórios (1996), de Bertrand Badie; A mundialização - o fim das fronteiras (1997), de Philippe Defarges; O fim do EstadoNação (1999), de Kenichi Ohmae, entre outras.

No campo das Relações Internacionais, como destaca Halliday (1999, p. 89-90), a questão é mais complexa do que a polarização entre ser ou não ser "Estado-cêntrico", mas sim definir com mais clareza o que se entende por Estado e como se dá seu processo 
contraditório de fortalecimento/enfraquecimento. Na verdade, sequer é possível falar de soberania no sentido abstrato, mas sim a partir de como o governo efetivamente exerce o controle sobre seu território e população diante do contexto e dos condicionantes internacionais (HALLIDAY, 1999, p. 97). Nesse sentido, o discurso recorrente da fragilização da questão nacional expressou um misto de discurso ideológico e/ou desconhecimento histórico. Na verdade, a história de formação do sistema mundial é produto da dialética entre a integração global por meio da ampliação dos fluxos globais (transnacionalização) e a difusão das formações estatais modernas (internacionalização) (FERNANDES, 1998b). Em outras palavras, a expansão do capital e a nacionalização do poder, não só das forças armadas e das burocracias, mas de moedas, bancos e identidades, têm sido o motor do sistema internacional, numa engrenagem complexa de acumulação de poder e de riqueza e, com efeito, de competição e conflito (FIORI, 2009, p. 164-170). Ou seja, não faz sentido a própria separação rígida entre externo e interno, pois implica em negligenciar as clivagens e assimetrias que perpassam essa dialética de formação do sistema internacional. ${ }^{2}$

Apesar desse discurso predominante ao longo dos anos 1980, tem ocorrido justamente um recrudescimento das pressões competitivas interestatais e a projeção do poder predominante em escala global dos EUA. Para tanto, basta observar os conflitos relacionados à questão nacional que têm atravessado todo o período do Pós-Guerra Fria, tais como: a formação de novos Estados (na ex-Iugoslávia, ex-URSS, ex-Tchecoslováquia, Namíbia, Eritréia, Sudão do Sul); o recrudescimento de movimentos separatistas (Chechênia, Daguestão, Inguchétia, na Rússia; Xinjiang e Tibet, na China; no Cáucaso; no Curdistão; no País Basco); as próprias guerras civis e a consequente disputa pelo aparelho estatal (particularmente na África, como RD do Congo, Angola, Ruanda); a crescente

$2 \mathrm{Na}$ verdade, não há soberania absoluta internamente, nem igualdade absoluta externamente, de modo que está equivocada a premissa da crítica pósestruturalista desenvolvida por Ashley (1988), já que a soberania estatal jamais pode ser compreendida como subjetividade homogênea, estável e unitária. 
disputa por recursos naturais (petróleo, diamantes, gás natural); o recrudescimento do protecionismo comercial; a formação de novas coalizões políticas interestatais (G20, IBAS, BRICS); o ativismo das diplomacias em instituições internacionais (ONU, OMC, FMI); o uso dos instrumentos políticos nacionais para o desenvolvimento e/ou superação da crise ('guerra cambial'); a intensificação das operações subterrâneas e intervenções militares (golpe na Venezuela, 'revoluções coloridas', desestabilização da Síria); as novas demandas por ações nacionais diante das ameaças transfronteiriças (SARS, terrorismo, tráfico de drogas, armas e contrabando, etc.); e o próprio fato de os países mais bem sucedidos em termos de inserção internacional terem sido os que consolidaram projetos nacionais, como os países do Leste da Ásia (China, Tigres).

Na verdade, o que ficou conhecido como agenda neoliberal (e a consequente fragilização da questão nacional) representou a projeção de forças políticas que estiveram na defensiva durante boa parte do século XX, com o predomínio de projetos keynesianos, nacionalistas e socialistas; ou da resistência apresentada pelo bloco soviético às potências ocidentais. Como destaca Losurdo (2006, p. 357-60), a tradição liberal reforçou o "espaço sagrado" dos livres e proprietários contra o "espaço profano" dos grupos sociais subalternos, utilizando-se dos meios políticos e econômicos, da lei e da força para ampliar seu domínio social. ${ }^{3}$

No plano internacional, a atuação das grandes potências combinou dois vetores voltados a fragilizar o Estado soberano e suas políticas de desenvolvimento, bem como projetar seus poderes por meio do alargamento das atribuições das organizações internacionais. De um lado, as grandes potências desenvolvidas passaram a impor aos países periféricos, por meio de organismos internacionais como FMI, BIRD e OMC, restrições às políticas de desenvolvimento visando 'chutar a escada' (CHANG, 2004; 2009)

3 Segundo o mesmo autor, o Liberalismo soube, contudo, se apropriar de parte das práticas de seus opositores e, sobretudo, reforçar o discurso sobre uma suposta paternidade da liberdade 'em geral', de modo que o que hoje predomina é sua transfiguração hagiográfica. Para um debate aprofundado sobre a história do Liberalismo, ver Contra-história do Liberalismo (LOSURDO, 2006). 
e abrir novas fronteiras de acumulação. É ilustrativo o caso da criação do OMC, com maiores compromissos e obrigações para os seus participantes em temas de investimento (TRIMS), de serviços (GATS) e de propriedade intelectual (TRIPS). De outro, estas mesmas potências, lideradas pelos EUA, atuaram visando ampliar seus domínios, sobretudo, em áreas de interesse estratégico, como o entorno da Rússia e do Grande Oriente Médio, incluindo confrontar países que insistiam em ter uma inserção autônoma ou desafiante. Os EUA começaram a trabalhar conceitos como "ataque preventivo" a partir da Doutrina Bush (2002) e sua Guerra ao Terror. E o Conselho de Segurança da ONU passou a utilizar conceitos de "intervenção humanitária" e "direito de proteger". A securitização e o alargamento da agenda de segurança frequentemente tornam-se uma espécie de intervencionismo institucional, através do qual as grandes potências alargam seus domínios de atuação internacional, recrudescendo ainda mais a assimetria de poder no sistema internacional.

$\mathrm{O}$ universalismo tem historicamente se confundido com o etnocentrismo e com o imperialismo. Não raro as grandes potências mobilizam discursos voltados a assegurar a 'paz' e expandir a 'civilização', o 'mercado livre' e o 'direito', enquanto projetam seus poderes em escala global, desde o colonialismo do século XVI às intervenções estrangeiras contemporâneas. No Pós Guerra Fria, tem sido recorrente as intervenções, violações institucionais e crimes de guerra, como nos casos da invasão do Panamá, da Iugoslávia, do Iraque pelos EUA nos anos 1990 (LOSURDO, 1999, p. 87-88), ou no Afeganistão, Iraque novamente e Líbia no século XXI - para ficar nas mais importantes.

Todavia, se durante o século XIX houve o predomínio da agenda liberalizante, ao longo do século XX, e, sobretudo após a crise de 1929 , houve um longo período de desenvolvimento polarizado por diversos arranjos anti (ou pelo menos, não) liberais (FERNANDES, 1998, p. 19). Da mesma forma, após a supremacia neoliberal nas décadas de 1980-90, o início do século XXI tem representado a retomada da questão nacional e de suas políticas de desenvolvimento. Em outras palavras, há uma reação crescente refletida tanto no desgaste da agenda liberalizante, que aprofundou a 
marginalização na América Latina nos anos 1990 e projetou a crise e o esgarçamento do tecido social na Europa desde 2008, quanto no espiral de unilateralismo e militarismo das grandes potências, que resultou em inúmeras intervenções desestabilizadoras já citadas (Afeganistão, Iraque e Líbia), além da guerra civil na Síria e as pressões contra Irã e Coréia do Norte, por exemplo.

Contudo, a expansão neoconservadora do poder norte-americano, o declínio relativo das capacidades do centro do sistema, a projeção dos países emergentes e o fortalecimento da interação Sul-Sul têm influenciado as novas configurações de poder no mundo. Mais do que isso, tal dinâmica tem recolocado a questão nacional, o desenvolvimento e a soberania no centro da política internacional contemporânea. Ao longo do Pós-Guerra Fria ocorreu uma mudança de identidade e, consequentemente, uma convergência de interesses entre os BRICS, na medida em que o discurso cada vez mais tem se voltado à agenda do desenvolvimento e da multipolaridade.

Trata-se, na essência, de recuperar tendências projetadas com o ciclo de descolonização do Pós-Guerra, quando as lideranças chinesas (Chu En-lai) e indianas (Nerhu) lançaram a diplomacia dos Cinco Princípios da Coexistência Pacífica em 1955 em Belgrado, que, posteriormente, converteu-se na base do Movimento dos Países Não-Alinhados (1961), da Conferência das Nações Unidas para Comércio e Desenvolvimento (UNCTAD) e do G-77. Num sistema internacional anárquico e assimétrico, aderir ao princípio westfaliano de soberania representava um mecanismo de preservação da autonomia dos países periféricos e, por extensão, um meio para levar adiante o desenvolvimento e a (re)construção nacional. Por essa mesma razão que Lênin sustentou a autodeterminação das nações como concepção progressista ${ }^{4}$ diante do imperialismo da virada dos séculos XIX-XX (LÊNIN, 1979),

\footnotetext{
4 Para tanto, basta observar que a agenda da soberania pautou todos os movimentos nacionalistas, socialistas e antiimperialistas. Recomenda-se a leitura dos discursos de Che Guevara, Allende, Chávez e Arafat nas Nações Unidas, reunidos no livro Soberania e autodeterminação (2007).
} 
influenciando o movimento comunista e os países que superavam o domínio neocolonial ao longo do século XX.

$\mathrm{Na}$ atualidade, o agrupamento BRICS tem retomado parte da agenda dos então países não-alinhados. É nítida a defesa da reforma da governança mundial, incluindo, por exemplo, uma nova "arquitetura financeira mais representativa", as "reformas das cotas" e um "processo aberto" para escolha das direções do FMI e Banco Mundial; a prioridade ao desenvolvimento expresso na busca por criar um novo Banco de financiamento próprio e por tornar a UNCTAD no "ponto focal" do sistema da ONU para temas de comércio e desenvolvimento; a defesa e o "compromisso com a diplomacia multilateral"; a busca por redução das assimetrias por meio de ações como os Objetivos de Desenvolvimento do Milênio; e o respeito à soberania ${ }^{5}$ ao enfatizar soluções políticas para soluções de conflitos, ou mesmo saudando a União Africana por ter assumido papel central na resolução dos conflitos no continente. ${ }^{6}$ Em outros momentos ou em discursos isolados, a ênfase tem sido dada na crítica ao unilateralismo e na defesa da cooperação Sul-Sul.

Assim, a retomada da questão nacional é parte de um amplo reordenamento de poder. A relativização da soberania e a fragilização das políticas de desenvolvimento nos países periféricos (e em desenvolvimento) foram parte da estratégia de expansão do poder dos EUA/Ocidente após o fim da Guerra Fria. Contudo, este ciclo parece ter se esgotado; e a ascensão dos BRICS, o relacionamento no eixo Sul-Sul e todo o rearranjo nele implicado estão relançando a questão nacional como prioridade. Daí a importância de discutir a inserção da África Subsaariana e o papel dos países emergentes.

5 Claro que é preciso separar discursos de interesses práticos e estratégicos desses mesmos países. É o caso, por exemplo, da Rússia, que utilizou o conceito de Responsabilidade de Proteger para intervir na Geórgia em 2008 sob alegação de defesa da população de origem russa na Ossétia do Norte.

6 Ver documentos das Quarta e Quinta Cúpulas dos BRICS, por exemplo. Disponível em: <http://www.itamaraty.gov.br/search?SearchableText=c\%C3\% BApulas+brics>. Acesso em: 13 jun. 2013. 


\section{A ÁFRICA SUBSAARIANA E O PAPEL DOS PAÍSES EMERGENTES}

A superação do ciclo neocolonial (1860-1960) na África combinou múltiplos desafios, tais como, a persistência de guerras civis, em alguns casos ainda no bojo da descolonização (com destaque para as colônias portuguesas); a complexa formação dos Estados nacionais; a inserção internacional condicionado pelas grandes potências (EUA, URSS e ex-metrópoles coloniais, como França e Grã-Bretanha); a marginalização do sistema internacional e a vulnerabilidade socioeconômica relacionada com a imposição da agenda liberalizante nos anos 1990; e o recrudescimento de conflitos e da instabilidade política.

Diante do cenário de exclusão do ciclo de globalização, a imposição de reformas liberalizantes e crises de governança, as empresas e países recuaram de suas posições na região, relegando o continente ao segundo plano (LOPES 2007, p. 18). Sem cooperação e investimentos, combinado com a baixa no preço das commodities na década de 1990, houve um colapso do comércio exterior e do PIB destes países, dependentes de um ou no máximo dois produtos agrícolas, minerais e/ou energéticos. O Banco Mundial informou que a renda per capita caiu de U\$ 573 (1991) para U\$ 470 dólares (2002) na África Subsaariana, refletindo um cenário desalentador. ${ }^{7}$

Apesar disso, a África Subsaariana tem apresentado uma trajetória econômica e política de recuperação, depois dos percalços dos anos 1980-90. No campo econômico, mesmo partindo de um patamar muito baixo, deve-se constatar a superação de parte relevante dos percalços, como ilustram as altas taxas de crescimento econômico, a inflação média de um dígito, a ampliação do volume de investimentos estrangeiros (IED) e a estabilização das contas nacionais (LOPES, 2007, p. 21). Apesar dos patamares baixos, o Banco Mundial indica que PIB per capita mais do que dobrou em uma década (2002-2012), passando de U\$ 470 para U\$ 1.345 dólares e a expectativa de vida ao nascer foi de 50 para 55 anos

7 Ver dados do Banco Mundial disponível em: <http://data.worldbank.org/ region/SSA >. Acesso em: 05 dez. 2011. 
em uma década (2001-2011). ${ }^{8}$ No campo político, houve fortalecimento institucional e progressiva estabilização política, com a resolução de inúmeros conflitos civis e regionais (SARAIVA, 2008) - apesar da persistência de conflitos crônicos do Chifre da África e/ou na África Ocidental, por exemplo.

A África é umas das últimas fronteiras do sistema internacional, nos âmbitos econômicos, diplomáticos e demográficos. Lopes (2007, p. 21-22) destaca que o crescimento econômico do continente africano tem sido acima da média mundial, com destaques como Angola e Mauritânia que tiveram crescimento de dois dígitos nos últimos anos; a evolução de 200\% no recebimento de IED entre 2000 e 2005 (de U\$ 7 para U\$ 23 bilhões de dólares); a capitalização da Bolsa de Johanesburgo foi superior à da Bovespa e à de Shangai; o crescimento mais rápido de telefonia celular entre os continentes, etc. No âmbito diplomático, depois da marginalização africana nos anos 1990, voltou a ter iniciativas próprias e ser disputado por novos atores, especialmente os emergentes (China, Brasil e Índia). No âmbito demográfico, apesar das contradições intrínsecas ao início da transição demográfica, nota-se uma progressiva urbanização, melhora da expectativa de vida e redução das taxas de fecundidade.

Apesar da trajetória recente, de um modo geral persiste na África as contradições relacionadas à formação do moderno sistema interafricano pós-colonial. Primeiro, o baixo nível de institucionalização da vida política, revendo uma débil formação do aparelho estatal, o que dificulta desde o provimento de políticas governamentais até a imposição da ordem pública. Segundo, a dificuldade em fazer com que o crescimento e a estabilidade da economia proporcionem desenvolvimento de forma mais extensiva. Terceiro, um conjunto de mazelas que inclui a forte penetração do narcotráfico internacional, assim como outras formas de criminalidade, como o contrabando de recursos preciosos. Por fim, a persistente vitimização em parte estimulada por iniciativas humanitárias durante a década de 1990, que além de limitadas

8 Ver dados do Banco Mundial disponível em: <http://data.worldbank. org/region/SSA >. Acesso em: 05 dez. 2011. 
vantagens práticas para a população-alvo, por vezes reforçou esquemas de corrupção e dependência econômica imposto pelas elites (SARAIVA, 2010, p. 172-73).

Mais do que isso, a África, ressalte-se, que além de ser o continente com a pior situação econômica e política, possui amplas desigualdades internas. Como ilustra o relatório do Banco Mundial acerca da região Subsaariana: a Nigéria e a África do Sul representam 50\% do PIB nominal; O PIB per capita da Guiné Equatorial é 83 vezes superior ao de Burundi; o PIB da África do Sul é 791 vezes maior do que o da Guiné Bissau; a agricultura representa 3\% do PIB da África do Sul e 55\% da República Centro Africana; o Zimbábue tem taxa de alfabetização de 92\% e o Chade de 33\%; nas ilhas Seicheles há 961 telefones por mil e na Eritreia, 28; em Ruanda se tem 56\% de mulheres no Parlamento, contra 3\% nas ilhas Comores. ${ }^{9}$ Entre a África do Norte e a Subsaariana, as desigualdades são pronunciadas, não somente do ponto de vista histórico e civilizacional, mas também de seus indicadores: atualmente, o PIB per capita da África do Norte é de 3.280 dólares, contra 1.130; o número de telefones por 100 habitantes é de 88, contra 38; a população é de 166,7 milhões, contra 841 milhões; o crescimento populacional é de $1,6 \%$ ao ano, contra 2,5\%; a expetativa de vida é de 71,5 anos, contra 52,5; a taxa de fecundidade é de 2,6, contra 5,0; a mortalidade infantil é de 22,8 por mil nascidos vivos, contra $80,8 .^{10}$

No plano internacional, a o fortalecimento dos Estados nacionais tem permitido, de um lado, a criação de mecanismos de auto-organização e de integração regional como NEPAD, SACU e SADC e, de outro, a retomada de algum protagonismo diplomático pelos países africanos, seja na resolução de problemas regionais através da União Africana, seja no envolvimento em coalizões

9 Ver o Africa Development Indicators 2011 do Banco Mundial. Disponível em: <http://web.worldbank.org/WBSITE/EXTERNAL/COUNTRIES/AFRICAEXT/0, contentMDK:20563739 menuPK:1613741 pagePK:146736 piPK:146830 theSit ePK:258644,00.html>. Acesso em: 05 dez. 2011.

10 Ver o The little data book on Africa 2011 do Banco Mundial. Disponível em: $<$ http://siteresources.worldbank.org/INTAFRICA/Resources/LDB-Africa_2011. pdf>. Acesso em: 05 dez. 2011. 
com outros países, num destaque especial para iniciativas ligadas aos países emergentes, como a Cúpula América do Sul-África (ASA) e os Fóruns Índia-África (FIA) e de Cooperação China-África (FOCAC), além de outras articulações que envolvem a África do Sul (IBAS e BRICS). Com a crise dos países centrais e o consequente recuo destes do continente africano, os países da África subsaariana incrementaram sua atuação externa através da barganha com os países emergentes.

Essa atuação externa importante de China, Brasil e Índia no continente africano revela não só o protagonismo dos países emergentes, nem se restringe apenas a nova realidade africana. Revela, isto sim, que a Europa tem perdido ímpeto em sua presença no continente, apesar das ambições franco-britânicas, em parte devido às prioridades dada à expansão europeia para Leste e às crises do continente que se acentuaram desde 2008, manifesto nas instabilidades financeiras e políticas. Da mesma forma, os EUA têm priorizado o Grande Oriente Médio, em especial depois do 11 de Setembro de 2001, deixando este vácuo na África para os países emergentes. Para a África, se a década de 1990 representou a marginalização do continente, a presença crescente dos países emergentes representa a possibilidade de barganhar a inserção internacional no século XXI (ZAFAR, 2007). Ao invés de objeto, no continente subsaariano também existem atores que buscam melhores oportunidades de desenvolvimento e inserção internacional, não obstante as contradições.

\section{CHINA, BRASIL E ÁFRICA SUBSAARIANA: RETOMADA DA QUESTÃO NACIONAL?}

China e Brasil têm apresentado comportamentos distintos desde a década de 1980. O Brasil encerrou um longo e virtuoso ciclo de crescimento iniciado nos anos 1930, já a China consolidou seu desenvolvimentismo, após os percalços ocorridos desde a Revolução Chinesa (1949). No caso da África, o Brasil recuou do continente a partir dos anos1990, justamente no contexto em que a China retomou sua presença nessa região do mundo. Nesse sentido, embora se reconheça os dois países como emergentes 
(dado que estavam fora do núcleo do poder mundial do Atlântico Norte e agora vem sua situação relativa melhorar) é preciso reconhecer as assimetrias entre Brasil e China. Enquanto o primeiro ainda preserva uma condição de potência regional - mesmo que com ampliado ativismo durante o governo Lula -, a China já é uma potência global - mesmo que insatisfeita com a sua posição na governança global.

Essas diferenças se acentuaram em razão da diferença de padrão de inserção internacional, sobretudo nos anos 1990. O Brasil cedeu às políticas liberalizantes irradiadas do Consenso de Washington (1989), desmontando seu projeto nacional e optando por uma forma de inserção internacional circunscrita ao eixo vertical (Norte-Sul) e à integração - essencialmente comercial - no Cone Sul. Havia a concepção de que a busca da credibilidade frente aos países centrais teria como contrapartida "reconhecimento político, concessões comerciais e ajuda financeira e tecnológica" (PECEQUILO, 2008, p. 138-141). O que se percebeu foi um progressivo desmonte do projeto nacional a partir da adoção de reformas liberalizantes; da adesão sem contrapartida aos regimes internacionais (Tratado de Não-Proliferação de Armas Nucleares-TNP e Regime de Controle de Tecnologia de Misseis-MTCR); da desmobilização da agenda da diplomacia brasileira no sistema internacional e do refluxo econômico-comercial em outras regiões, especialmente em países periféricos. Durante o governo Fernando Henrique tal trajetória se aprofundou; e ao supor insuficiência de poder, a busca de credibilidade e ingresso na globalização implicou mais concessões do que ganhos de espaços, frustrando as expectativas e desgastando tal projeto político. No caso da África, ao reduzir o crédito para a exportação de bens e serviços e enxugar o corpo diplomático dedicado ao continente, o Brasil claramente alterou suas prioridades, perdendo participação econômico-comercial e política naquela região (SARAIVA, 2002, p. 10).

Já a China, além do acelerado desenvolvimento econômico e fortalecimento do seu projeto nacional, retomou e aprofundou a presença na África nos anos 1990, como parte da universalização de sua política externa. Em essência, o governo chinês respondia a necessidades objetivas, tais como 1) os riscos de isolamento 
internacional após a repressão na Praça da Paz Celestial, seguido do colapso do campo socialista; 2) a crescente demanda por hidrocarbonetos, alimentos e matérias-primas; 3) a busca por novos mercados diante do rápido incremento do comércio exterior chinês (PAUTASSO, 2009b). Na visão de acadêmicos chineses, a atuação do país na África encerra outros importantes aspectos, tais como: 1) um importante teste para a promoção do soft power chinês a partir da ajuda ao desenvolvimento (ALDEN, 2007); 2) e uma forma de afirmação de um sistema internacional mais equilibrado através da reafirmação de princípio de não-interferência em assuntos domésticos e de defesa da soberania (WENPING, 2007; ANSHAN, 2007).

No caso do Brasil, o governo Lula representou uma virada na diplomacia brasileira, a partir da adoção de uma estratégia autonomista, voltada à construção de coalizões com países periféricos (SOUZA, 2009, p. 21-23). A reorientação diplomática oriunda da mudança de modelo ficou mais transparente no caso da condução do relacionamento com a África. ${ }^{11}$ De um lado, percebe-se um ativismo político-diplomático, dado o fortalecimento de iniciativas anteriores (como a Comunidade dos Países de Língua Portuguesa/ CPLP) e criação de novas iniciativas diplomáticas que tem nos países africanos um foco especial, incluído o G20 no âmbito da OMC, o Fórum de Diálogo Índia, Brasil e África (IBAS), a Cúpula América do Sul-Países Árabes (ASPA) e a Cúpula América do Sul-África (ASA). De outro, o incremento do relacionamento entre as margens do Atlântico, com destacado papel do Departamento de Promoção Comercial e Investimentos do Itamaraty, da Agência Brasileira de Promoção das Exportações-APEX e do BNDES na

11 Além da reorganização administrativa do MRE, com a separação dos Departamentos de África e Oriente Médio e a criação de outra Divisão de África (DAF III), e a (re)abertura de 16 embaixadas, o presidente Lula viajou 12 vezes para a África, totalizando 34 visitas a 23 países em 8 anos de mandato destacando o simbolismo de a última viagem de governo (Maputo) e a primeira após encerrar o mandato (FSM - Senegal) terem sido nesse continente. A informação sobre as visitas a África foram dadas à Agência Brasil pelo subsecretário-geral de Assuntos Políticos do Ministério das Relações Exteriores, embaixador Piragibe Terragô. Disponível em: <http://agenciabrasil.ebc.com. br/web/ebc-agencia-brasil/enviorss/-/journal_content/56/19523/1105814 . . Acesso em: 20 ago. 2013. 
promoção do comércio e dos investimentos. Mas a cooperação voltada ao desenvolvimento tem assumido um papel chave, perceptível pelo incremento do orçamento da Agência Brasileira de Cooperação-ABC (que foi de 4,8 para 52 milhões entre 2002 e 2011) e atuação de instituições com grande capacidade técnica, casos da Embrapa, Fiocruz e Senai (ROSSI, 2011). Tem sido reconhecido o papel diferenciado do relacionamento do Brasil com a África (WHITE, 2013), sobretudo na transferência de conhecimento nos setores de agricultura tropical, de produção de energia renovável, de formulação de políticas de saúde e de combate à pobreza.

Embora não seja difícil reconhecer tanto a assimetria dos países emergentes em tela (China e Brasil) quanto a heterogeneidade dos países subsaarianos, é preciso reconhecer algumas caraterísticas importantes nesses relacionamentos. De um lado, a China tem apresentado uma capacidade financeira expressiva, fundamental ao financiamento do comércio e, sobretudo, das obras infraestruturas - estas que tem sido o núcleo de sua atuação junto aos países africanos. No caso do Brasil, inclusive em razão do enorme potencial em recursos naturais e energéticos, o país tem menos complementariedade e, em função das limitações financeiras, menor condição de alavancar o relacionamento. De todo modo, o governo Lula deu ênfase à região e centrou os esforços na exportação de políticas públicas de êxito no país, por meio da cooperação bi e trilateral. ${ }^{12}$

Não se trata, contudo, de esmiuçar a relação de China e Brasil com os países subsaarianos, mas analisar o papel destes países emergentes na retomada da questão nacional e, com efeito, no debate acerca de práticas neocoloniais ou subimperialistas. Para tanto, é preciso reconhecer que há notáveis assimetrias entre Brasil e China, entre estes e os países africanos, e é claro, entre demais países, inclusive no seio da OCDE ou da União Europeia. Afinal, os países têm diferentes trajetórias históricas, dimensões

12 Ver estudo do IPEA cujo título é Cooperação brasileira para o desenvolvimento internacional. Disponível em: <http://www.ipea.gov.br/portal/images/ stories/PDFs/Book_Cooperao_Brasileira.pdf S. Acesso em: 22 ago. 2013. 
geográficas, condições econômicas e capacidades estatais. O alargamento conceitual prejudica a capacidade explicativa e obscurece as relações centro-periferia. Mais do que obscurecer questões essenciais, tais enfoques ${ }^{13}$ esquecem que o desenvolvimento é contraditório, produz não o subdesenvolvimento, mas um processo desigual combinando de modernização e opressão/exclusão.

Daí a importância de pontuar algumas questões conceituais. Primeiro, atribuir perfil neocolonial à atuação sino-brasileira na África significa assumir o desconhecimento acerca da história do imperialismo do século XIX e mesmo as práticas atuais das principais potências, notadamente os EUA, em ingerência externas diretas e indiretas em diversas regiões do globo. Quando Lênin (1979) destaca a formação dos monopólios, fusões de capital industrial e bancário, exportações de capitais e partilha territorial entre as potências, está abordando características gerais da fase madura do capitalismo (imperialismo). Mas, da mesma forma, o mesmo autor reconhecia também o papel do financiamento e da apropriação de tecnologias no desenvolvimento da economia moderna. Na mesma linha, o desenvolvimento desigual do capitalismo combina forças centrífugas (concentração) e centrípetas (expansão/difusão) que alteram o balanço de poder no mundo, em processos de ascensão e declínio de polos econômicos. Em suma, um país periférico, apesar da dependência, pode 'queimar etapas' no processo de desenvolvimento, explorando o conjunto de interações entre o nacional e o internacional. ${ }^{14}$

Segundo, tal concepção reforça teses convenientes aos interesses das 'velhas potências' ocidentais. É irônico que as preocupações dos países ocidentais ocorram exatamente

13 As teses do subimperialismo brasileiro formuladas por Rui Mauro Marini identificam países (exemplo o Brasil) como subcentros da cadeia de reprodução do capital, ou elo dependente da cadeia imperialista. Embora partam de uma orientação marxista, conseguem concluir que a modernização, as obras de infraestrutura e a integração sul-americana são nocivas. Afinal, Brasil e EUA, de forma quase indistinta, apenas disputam a sistema de poder sul-americano (LUCE, 2007).

14 Já fizemos está discussão em outra oportunidade utilizando-se, entre outros autores, Ignácio Rangel (2005). Recomenda-se ainda a abordagem de Gilpin (1987) que trata do crescimento desigual e das 'mudanças estruturais' no sistema internacional. 
quando seu domínio se fragiliza nas suas antigas esferas de influência. Alguns autores, no mínimo ingênuos, consideram que as empresas chinesas se beneficiariam por atuar em comunhão com os interesses estatais ${ }^{15}$ (ALVES, 2010, p. 28) - como se o Ocidente utilizasse apenas as regras de mercado e do direito internacional. ${ }^{16}$ Um autor chinês (WENPING, 2007, p. 29) aponta, de forma clara, que "a acusação de neocolonialismo é, em grande parte, uma preocupação do Ocidente diante da crescente presença da China na África, ao invés da defesa de princípios humanitários."

Terceiro, não se pode sonegar a importância de alternativas à inserção internacional de países africanos. Portanto, além de aplainar diferenças estruturais, subestima-se a importância do financiamento externo e da cooperação técnica para o desenvolvimento de países recipiendários. Mesmo que o relacionamento não seja determinado pela lógica exclusiva da solidariedade, é possível reconhecer ganhos mútuos, até porque o desenvolvimento autocentrado é intrinsecamente inviável em um mundo complexo. ${ }^{17}$

Além disso, é preciso considerar que, apesar das assimetrias, há importantes pontos de convergência entre os países emergentes e os países periféricos, em razão da distribuição de poder no mundo. A estrutura do sistema internacional no Pós-Guerra moldou-se de maneira a excluir os países periféricos e emergentes dos mecanismos decisórios, como os organismos financeiros (FMI e BIRD) ou políticos, com uma participação limitada à Assembleia Geral da ONU (exceto China); e a bloquear o acesso aos mercados cêntricos, criando barreiras via subsídios e normas fitossanitárias,

15 É comum ainda acusar a China de pilhar os recursos naturais africanos. Contudo, embora seja notável o interesse chinês por tais recursos, o país oriental importa apenas 9\% do petróleo africano, contra 36\% da Europa e 33\% dos EUA (WENPING, 2007, p. 29-32).

16 O mesmo autor ainda reforça o discurso afirmando que a China concede "créditos sem condicionalidades", enfraquecendo "os esforços ocidentais na promoção de reformas que ampliem a transparência, a probidade e o accountability dos governantes africanos" (ALVES, 2010, p. 30).

17 Este talvez seja o caso da construção de Itaipu: embora tenha sido uma obra crucial para o desenvolvimento nacional, o financiamento brasileiro gerou um fluxo de recursos para o Paraguai que não seria possível com esforços próprios. Aliás, é o financiamento do Brasil, através do FOCEM (ver PAUTASSO, 2012), que está permitindo a construção das linhas de transmissão de energia elétrica até Assunção, sem o qual o país vizinho continuaria em dificuldades. 
enquanto são coagidos a abrir seus mercados. Ou seja, o relacionamento Sul-Sul torna-se uma alternativa crucial para resistir aos constrangimentos que os países periféricos e emergentes estão submetidos ao adotarem seus projetos de desenvolvimento nacionais não alinhados aos interesses ocidentais - do contrário, estes mobilizam suas estruturas de poder e seus princípios legitimadores, como "democracia", "direitos humanos" e "liberdade", para impor seus interesses. ${ }^{18}$

Em pleno século XXI, o (sub)imperialismo não pode ser reduzido à exportação de capitais, pois a questão nacional, a soberania, a autodeterminação e o desenvolvimento encerram uma complexidade infinita de variáveis. Se as relações interestatais estão impregnadas de interesses nacionais e corporativos, de conflitos e assimetrias, é preciso compreender os padrões de relacionamento, levando em conta a correlação de forças e as alternativas políticas em questão. Não se pode, pois, negligenciar que as relações sino-brasileiras com a África não têm tido a imposição de modelos político-institucionais e de ajustes macroeconômicos; não recorre a práticas de desestabilização e ingerências políticas e militares; tem proporcionado vantajosas condições de financiamento e disposição para a cooperação tecnológica; e ainda possuí uma agenda diplomática em muitos aspectos convergente no que se refere à reorganização da governança do sistema internacional.

Portanto, a presença dos países emergentes na África tem se constituído, de forma geral, num elemento de promoção da estabilidade e do desenvolvimento. Isto ocorre porque se apresentam como alternativa para os países africanos na busca por melhores condições de crédito, atração de novos investidores, obtenção de cooperação técnica, apoio ao fortalecimento da soberania e convergência diplomática para a desconcentração de poder no mundo, em especial em seus principais organismos multilaterais. Ou seja, a presença dos países emergentes tem sido não só essencial para a multipolarização, mas também para melhorar a posição relativa da África no cenário internacional.

18 Ressalte-se, apenas, que os princípios são mobilizados conforme os interesses estratégicos, como são os casos da aceitação da nuclearização de Índia, Paquistão e Israel, ou da convivência pacífica e afinada com regimes nada democráticos como os da Arábia Saudita, Turcomenistão, etc. Todos estes elementos, além dos desafios comuns ao desenvolvimento, compõem o quadro que explica a conveniência e o interesse da aproximação dos países periféricos com os países emergentes, para além da coação neoimperial. 


\section{CONSIDERAÇÕES FINAIS}

Analisando em perspectiva histórica, percebe-se que o mundo Pós-Guerra Fria tem sido caracterizado pela tentativa de alargamento dos recursos de poder das grandes potências. Tanto a imposição da agenda liberalizante quanto a intervenção militar são legitimadas pela ampliação dos atributos políticos das instituições internacionais - e quando não é possível, pela violação das mesmas, ainda que por vezes revestindo-se de argumentos 'humanitários', numa conversão do universalismo em etnocentrismo e imperialismo. Na verdade, a questão nacional não é um desafio para as potências ocidentais, isto é, a agenda política e acadêmica relativa à soberania e ao desenvolvimento estão (ou parecem) equacionados no âmbito doméstico. Ademais, as necessidades destas potências viabilizam-se justamente pela extensão de seus interesses em escala global por meio da força ou de seus regimes internacionais - o que pressupõe a flexibilização, justamente, da questão nacional. Não se trata, como é óbvio, de desacreditar as organizações interestatais e os regimes internacionais e seus mecanismos de governança. Mas sim alertar para o fato de que o alargamento das atribuições de tais organizações, sob domínio das grandes potências, acompanhado da consequente fragilização da soberania nacional, têm recrudescido a assimetria do sistema internacional. Em outras palavras, é preciso localizar as motivações e as contradições entre a questão nacional e as organizações e sistemas internacionais.

Na mesma linha, entende-se que o protagonismo dos países emergentes tem recolocado no centro do debate internacional a questão nacional - sem se colocarem como países que subvertem as instituições internacionais. Ou seja, a combinação entre a preservação da soberania e a construção de um maior equilíbrio no âmbito das organizações internacionais se constitui numa agenda importante aos países emergentes e periféricos. É esse o sentido de compreender a presença do Brasil e da China na África para além da descrição dos relacionamentos e de suas assimetrias; quer dizer, o papel dos países emergentes como forças não (sub)imperialistas, mas sim antiimperialista diante do quadro de forças que está posto. De resto, o risco de assimilar a formulação 
política e a produção acadêmicas dos países cêntricos pode cobrar um preço elevado...

\section{REFERÊNCIAS}

ALDEN, C. Emerging countries as new ODA players in LDCs: the case of China and Africa. Gouvernance Mondiale (IDDRI). Paris, n. 1, p. 1-14, 2007.

ALVES, A. Os interesses econômicos da China na África. Boletim de Economia e Política Internacional. IPEA, n. 1, p. 25-31, jan. 2010.

ANSHAN, L. China and Africa: policy and challenges. China Security. v. 3, n. 3, p. 69-93, 2007.

ASHLEY, R. Untying the sovereign state. Millennium: Journal of International Studies. v. 7, n. 2, 1988, p. 227-262.

BADIE, B. O fim dos territórios. Lisboa: Instituto Piaget, 1997.

BALAKRISHNAN, G. Um mapa da questão nacional. Rio de Janeiro: Contraponto, 2000.

CHANG, H. Maus Samaritanos - o mito do livre-comércio e a história secreta do capitalismo. Rio de Janeiro: Elsevier, 2009.

Chutando a Escada: a estratégia do desenvolvimento em perspectiva histórica. São Paulo: UNESP, 2004.

CHENAIS, F. Por trás do discurso da mundialização 'inevitável'. In: CARRION, R.; VIZENTINI, P. A crise do capitalismo globalizado na virada do milênio. Porto Alegre: UFRGS, 2000, p. 20-38.

DEFARGES, P. A mundialização - o fim das fronteiras. Lisboa: Instituto Piaget, 1997.

FERNANDES, L. As armadilhas da globalização. In: CARRION, R.; VIZENTINI, P. Globalização, neoliberalimo e privatização. Porto Alegre: UFRGS 1998a, p. 13-20.

. O Manifesto Comunista e o "Elo Perdido" do Sistema Internacional. Contexto Internacional. Rio de Janeiro, v. 20, n. 1, p. 219-234, jan./jun. 1998b. 
FIORI, J. O poder global e a nova geopolítica das nações. Crítica y Emacipación. primer semestre, 2009, p. 157-183

FUKUYAMA, F. O fim da história. Rio de Janeiro: Rocco, 1992. GILPIN, R. The Political Economy of International Relations. Princeton: Princeton University Press, 1987.

GUEVARA, C. et al. Soberania e autodeterminação. São Paulo: Expressão Popular, 2007.

LÊNIN, V. Obras escolhidas. vol. 1, São Paulo: Alfa-Ômega, 1979. LOPES, C. A África entre o Brasil e a China. Estudos AfroAsiáticos. a. 29, n. 1/2/3, p.13-27, 2007.

LOSURDO, D. Contra-história do Liberalismo. Aparecida-SP; Ideiasa \& Letras, 2006.

. Panamá, Iraque, Iugoslávia: Os Estados Unidos e as guerras coloniais do século XXI. Crítica Marxista. n. 9, p. 87-96, 1999.

LUCE, M. O subimperialismo brasileiro revisitado. IFCH/ Programa de Pós-Graduação em Relações Internacionais-UFRGS. Porto Alegre, 2007.

OHMAE, K. O fim do estado-nação. Rio de Janeiro: Campus, 1999.

PAUTASSO, D. O fortalecimento das relações Sul-Sul: estratégia e realidade para os países emergentes. Conjuntura Austral, v. 2, p. 48-62, 2011.

. A África no comércio internacional do Grupo BRIC. Meridiano 47 (UnB), v. 120, p. 54-59, 2010 a.

A Economia Política Internacional da China para Angola e os caminhos da transição sistêmica. Século XXI, v. 1, p. 107-126, 2010b.

A política externa chinesa e a $4^{a}$ Conferência do Fórum de Cooperação China-África-2009. Meridiano 47 (UnB), v. 112, p. 18-20, 2009a.

. O comércio exterior na universalização da Política Externa Chinesa no século XXI. Meridiano 47 (UnB), v. 113, p. 14-16, 2009b. 
.; ALBANUS, A. O Brasil e a Cúpula América do Sul-África: um país emergente nas relações Sul-Sul. Século XXI, v. 3, p. 79-95, 2012.

; AZEREDO, R. Expansão do poder dos Estados Unidos: o caso da Líbia. Tensões Mundiais, v. 7, p. 169-192, 2011.

PECEQUILO, C. S. A Política Externa do Brasil no Século XXI: os eixos combinados de cooperação horizontal e vertical. Revista Brasileira de Política Internacional. v. 51, n. 1, p. 136-153, 2008.

RANGEL, I. Obras Reunidas. Rio de Janeiro: Contraponto, 2 vol. 2005.

SARAIVA, J. F. S. A política externa do Governo Lula: o desafio africano. Revista Brasileira de Política Internacional. Brasília. v. 45, n. 2, p. 5-25, 2002.

A África na ordem internacional do século XXI: mudanças epidérmicas ou ensaios de autonomia decisória? Revista Brasileira de Política Internacional. Brasília. v. 51, n. 1, p. 87104, 2008.

The new Africa and Brazil in the Lula era: the rebirth of Brazilian Atlantic Policy. Revista Brasileira de Política Internacional. Brasília. v. 53, n. 1, p. 169-182, 2010.

SOUZA, A. Agenda Internacional do Brasil. São Paulo: Campus, 2009.

WENPING, H. The balancing act of China's Africa policy. China Security. v. 3, no.3, p. 23-40, 2007.

. Overturning the Wall: building China's soft power in Africa. China Security. v. 6, n. 1, p. 63-69, 2010.

WHITE, L. Emerging powers in Africa: Is Brazil any different? South African Journal of International Affairs, v. 20, n. 1, p. 117-136, 2013.

ZAFAR, A. The growing relationship between China and SubSaharan Africa: macroeconomic, trade, investment, and aid links. Oxford Journals - World Bank Research Observer. v. 22, n. 1, p. 103-130, 2007. 